\title{
THERMOVISUAL MEASUREMENTS OF 3D PRINTING OF ABS AND PLA FILAMENTS
}

\author{
Łukasz Zgryza', Anna Raczyńska', Magdalena Paśnikowska-Łukaszuk ${ }^{1}$ \\ 1 Fundamentals of Technology Faculty, Lublin University of Technology, Nadbystrzycka 38 Str., 20-618 Lublin, \\ Poland, e-mail:m.pasnikowska-lukaszuk@pollub.pl
}

Received: 2018.06.18

Accepted: 2018.08.02

Published: 2018.09.01

\begin{abstract}
This paper presents the use of 3D printing and discusses two types of materials used in 3D printing, i.e. ABS (Acrylonitrile Butadiene Styrene) and PLA (Polylactide). Next, it presents the thermovisual measurementscarried out on 3D printed samples (FDM method - fused deposition modelling) of these materials. The temperature zones that occurred during printing were determined. The geometrical dimensions of samples from the same material that were printed under different conditions were compared. The height of the printed object has a large influence on temperature distribution on its surface and the printing time does not differ significantly when printing with PLA or ABS.
\end{abstract}

Keywords: thermovisual measurement, 3D printers, ABS, PLA, FDM.

\section{INTRODUCTION}

3D printing is an additive production method involving the extrusion of thermoplastics by a moving nozzle with an appropriate diameter [3, 4]. The movements are programmed in such a way that successively overlapping layers of material create the desired object. One of the most important parameters in this process isthe temperature of the printer's heating elements, most often the head and the table. Materials which are used for 3D printing in FDM technology are called filaments and appear in aform of a thin monofilament wound on a reel. The most commonly used filaments are ABS and PLA.

The PLA, or polylactide, is a completely biodegradable polymer obtained from renewable natural resources (Fig. 2a). The prints created from it have a slightly shiny surface, and during cooling down the shrinkage that occurs in them is so small that it has no significant effect. This feature allows you to use a fan during printing, which cools the printed material immediately after leaving the nozzle. Thanks to such a treatment,
PLA layer cures faster, which in turn enables printing of partially protruding fragments without the use of supports. Polylactide does not dissolve in acetone, therefore, its smoothing or removal is difficult. The operating temperatures for the PLA used during the tests (Devil Design, thickness $1.75 \mathrm{~mm}$ ) cover the range of $200-235^{\circ} \mathrm{C}$ for the head and $50-60^{\circ} \mathrm{C}$ for the heated table (it is not required, but it improves the adhesion of the print to the substrate).

The ABS, or acrylonitrile-butadiene-styrene copolymer, is a material widely used in various industries (Fig. 2b). In contrast to PLA, ABS is not biodegradable and releases harmful nanoparticles during printing. Print-outs from this material are characterized by a matt surface and noticeable shrinkage during cooling (because of this, high printouts may crack during printing). Therefore, it is advisable to switch off the fan cooling the filament on the nozzle. ABS is soluble in acetone, which facilitates subsequent smoothing of the surface. The working temperature range for the ABS used in the study (Devil Design, thickness $1.75 \mathrm{~mm}$ ) is $230-240^{\circ} \mathrm{C}$ for the 


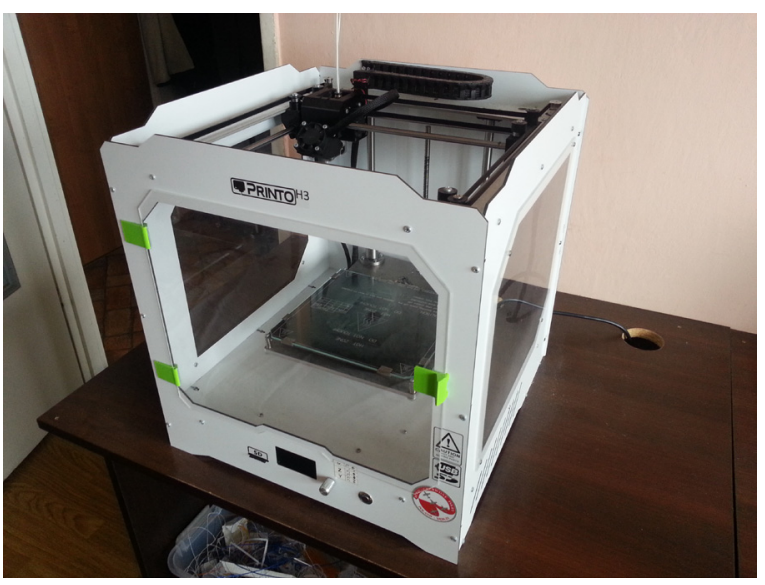

Fig. 1. 3D printer Printo3D H3

head and $90-100^{\circ} \mathrm{C}$ for the table [1]. The printer on which the tests were carried out is Printo3D H3. It has been equipped with additional side walls and a front door made of plexiglass with a thickness of $2.5 \mathrm{~mm}$, which help maintain a constant temperature in the working space. The printer has a table with a heating plate marked with the symbol "PCB Heatbed MK2B DUAL POWER" (Fig. 1), whose maximum stable working temperature reaches $100^{\circ} \mathrm{C}$ (depending on the ambient temperature).

To heat the heating block of the head, a $40 \mathrm{~W}$ cartridge heater is used, supplied with $12 \mathrm{~V}$ voltage, which allows to obtain the maximum head working temperature of about $290^{\circ} \mathrm{C}$. The nozzle in the head has a hole with a diameter of $0.4 \mathrm{~mm}$. Temperature measurement by the printer is carried out using two thermistors with the designation "NTC 100k 3950", one for the heating block and the table heating plate. There is a glass place on the heating plate, which is a table surface, 3 $\mathrm{mm}$ thick [2]. Depending on the shrinkage of the material used, as a result of irregular temperature distribution during printing in the resulting object stresses may occur. They result from the fact that a part of the material with a lower temperature begins to reduce its volume while the rest of the material is still heated. The accumulation of this type of stress in the material may even cause cracks. Thermovisual measurements can show place for the most vulnerable cracks [6]. Due to the large ratio of the surface area to the volume, thin-walled objects are most exposed. The height of the object also has an impact, because successive layers of the material being extruded are farther away from the surface of the heating table, so keeping them at a constant temperature is becoming more and more difficult.

\section{PRINTING MATERIALS AND METHODS}

The 3D model of the sample was created in the Autodesk Inventor 2016 engineering graphics program, while ".gcode" files were generated in the Cura 2.3.1 program. The cylinder model for printing has the following dimensions: outer diameter $9 \mathrm{~mm}$, inner diameter $7 \mathrm{~mm}$, height $190 \mathrm{~mm}$. It has been set to print in a vertical position. The density of the filling is: $100 \%$, and the thickness of a single layer is $0.28 \mathrm{~mm}$. In order to ensure that the sample adheres properly to the table surface, a margin surrounding the first layer for 12 additional lines around is used for both materials. In addition, before printing, the surface of the printer table was covered with a Dimafix spray adhesive. The tests were carried out on samples from Devil Design materials. Materials of the same type, but from different producers may differ.For the PLA printed sample, the fan cooling fan speed was set to $100 \%$. The temperature of the heating table was set in the program at $60^{\circ} \mathrm{C}$, while the temperature of the nozzle heater
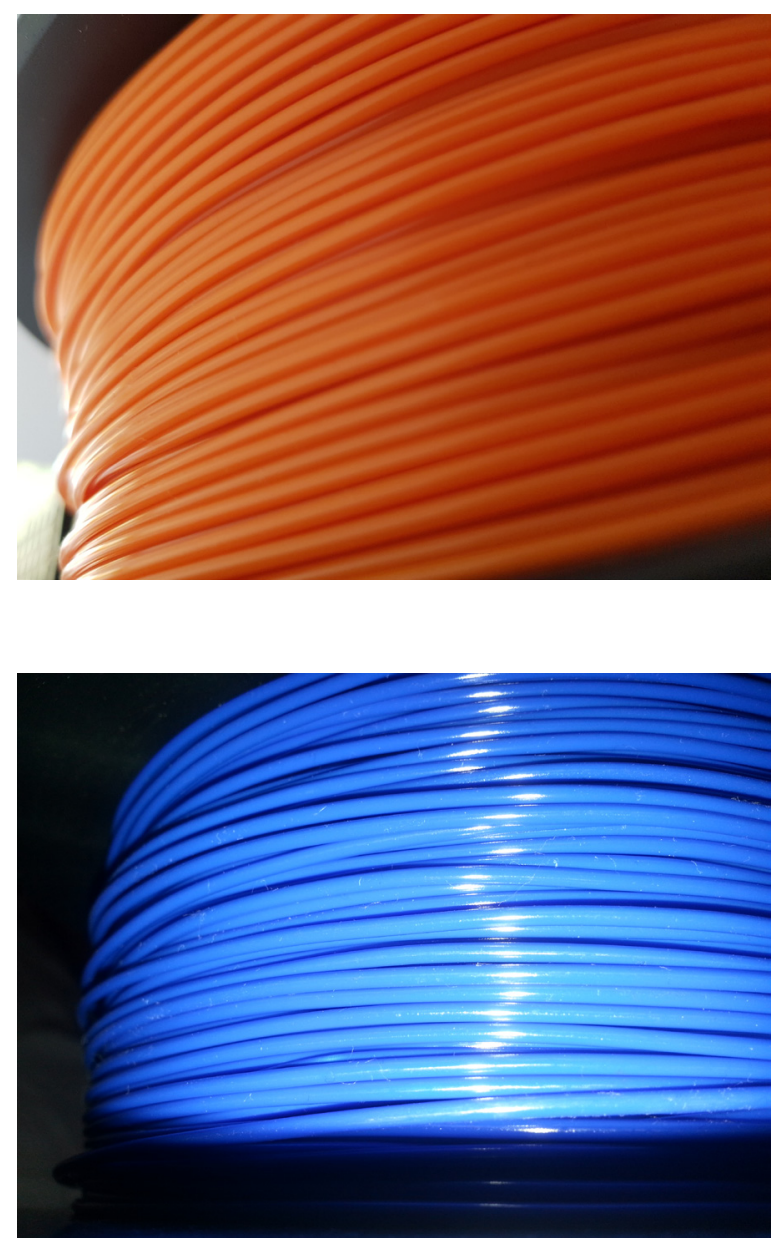

Fig. 2. The materials used: a) PLA b) ABS 
was set at $220^{\circ} \mathrm{C}$. The estimated time of printing on such settings determined by the program was 59 minutes, and the material used was estimated at 9 grams, which is the equivalent of 3.28 meters of filament thread with a diameter of $1.75 \mathrm{~mm}$. The actual time of printing the PLA sample was 1 hour 3 minutes.

For a sample printed from ABS, the cooling fan was switched off, this is due to the characteristics of this material (greater shrinkage than in PLA). The temperature of the heating table was set to $95^{\circ} \mathrm{C}$, and the temperature of the heating block heater at $235^{\circ} \mathrm{C}$. The print time of such a sample estimated by the program was also 59 minutes (the printing speed has not been changed). The amount of material used estimated by the program was 8 grams, equivalent to 3.28 meters of filament with a diameter of $1.75 \mathrm{~mm}$. The actual duration of such a printout was 1 hour 8 minutes, the difference in the actual print time results from the higher temperatures to which the printer components had to warm up before printing.

\section{RESULTS OF MEASUREMENTS}

Thermovisual measurements were performed to present the temperature distribution during $3 \mathrm{D}$ printing. Thermovisual measurements during the printing process consisted of taking pictures with a FLIR T440bx Infrared Thermal Imaging Camera. In order to execute print shots visible from the front of the printer, the door was opened, because otherwise the presence of the plexiglass cover prevented the printing space from being captured (Fig. 3).

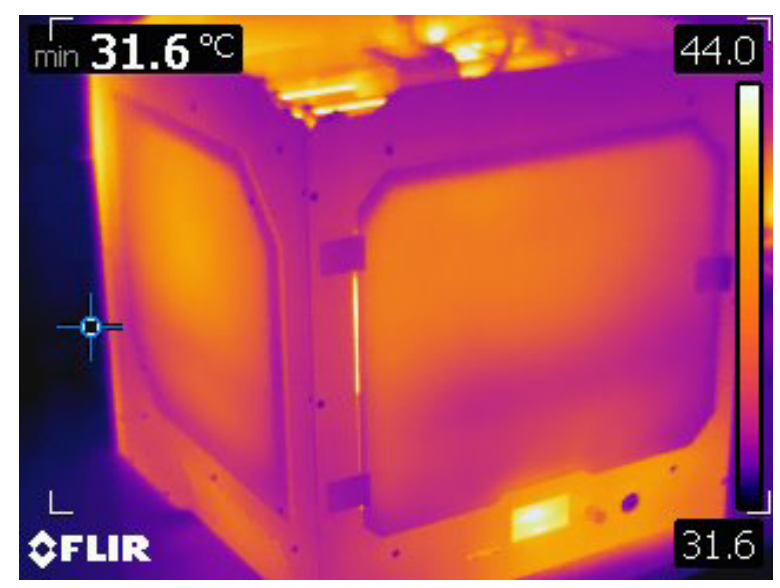

Fig. 3. A thermal image of the printer with visible Plexiglas covers that prevent photographing of an ongoing printout

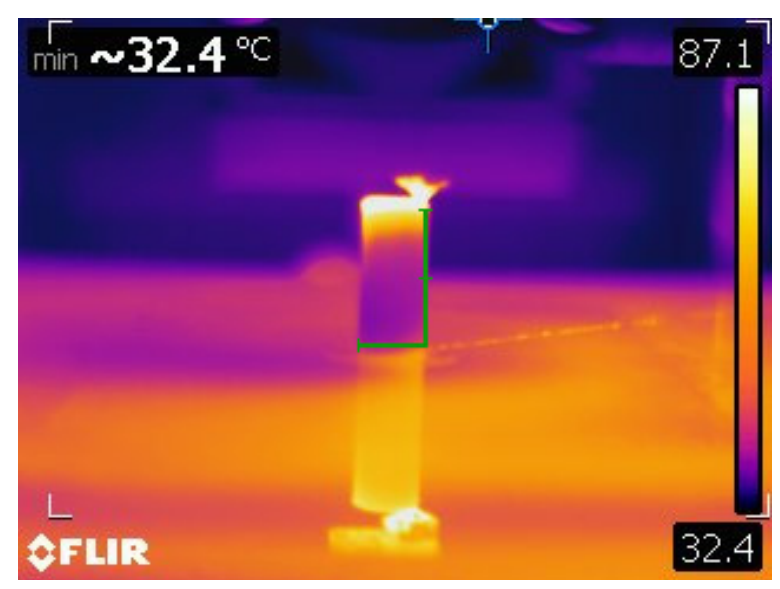

Fig. 4. PLA sample on about $11 \%$ of the printout

The temperature image can be seen in the thermovision image. Such measurements are also useful during simulation processes [5]. Measurements of the geometrical dimensions of the printed samples were made with a mechanical caliper with an accuracy of $0.02 \mathrm{~mm}$. During printing both from PLA and ABS samples showed a complex temperature distribution on their surface. Figure 4 shows the sample at the beginning of the printing process (about $11 \%$ of print) when it is still relatively low in relation to its target height. At this stage, the temperature of the sample does not change significantly with height, the exception is warmed, freshly embossed material on top. It is also visible reflection of the temperature spectrum from the glass that is the surface of the table, which was registered by the camera.

Thermal zones observed on the sample surface can be divided into three segments. The first one is the hot zone at a temperature of about $60^{\circ} \mathrm{C}$, the third is the cold zone, the temperature of which does not differ significantly from the temperature of the immediate environment of the printout in the working space. Between them there is a second, transitional zone, which is a smooth transition between the hot and cold zone. On the measurement made during about $34 \%$ of printout completion (Fig. 5), they have the following dimensions: the hot zone is about half the sample diameter both from the bottom and top, the transition zone is about one and a half times the sample diameter, it is also of similar size from the side of the table and from the head side. The remaining part of the sample height is the cold zone, which, however, is not yet well-defined.

In the later stages of printing, the size of individual zones changed. In the picture taken during about $50 \%$ of completion of print (Fig. 6), a differ- 


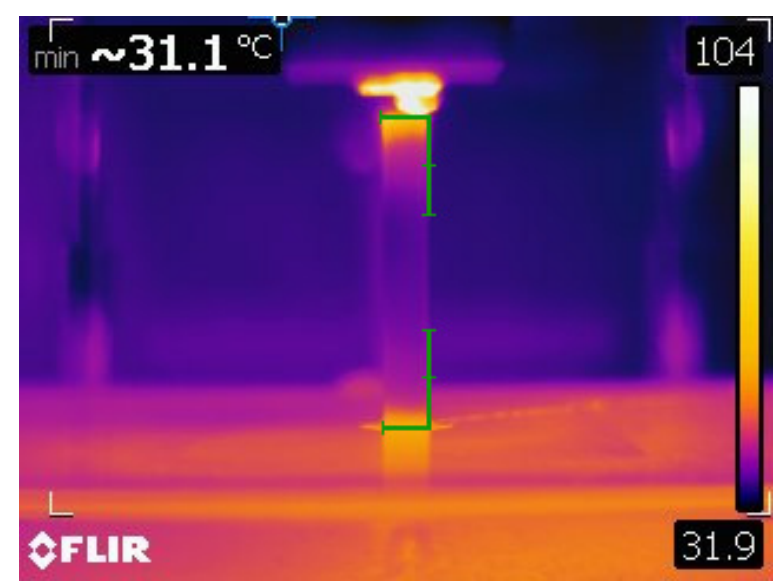

Fig. 5. PLA sample on about $34 \%$ of the printout

ent distribution of temperatures on the surface of the sample can be observed. The height of the hot zones does not differ significantly from those recorded in the previous measurement, both at the bottom and at the top of their height is about half a diameter. Transition zones have been enlarged, which are now about two diameters above and about four diameters at the bottom. The cold zone is clearly outlined.

Figure 7 shows a sample photo taken immediately after printing. In the upper left corner there is a trolley with a head that has reached its zero point. The registered distribution of thermal zones is as follows: the hot zone at the top has a height of about three-quarters of the diameter, while the upper transition zone has a height of about two and three-fourths of the diameter. At the bottom, the distribution is as follows: the hot zone is about half the diameter of the sample, and the transition zone is high at about six diameters.

After printing the sample made of PLA and cooling it, it was peeled off the table. The margin of the first layer was removed, and its geometrical

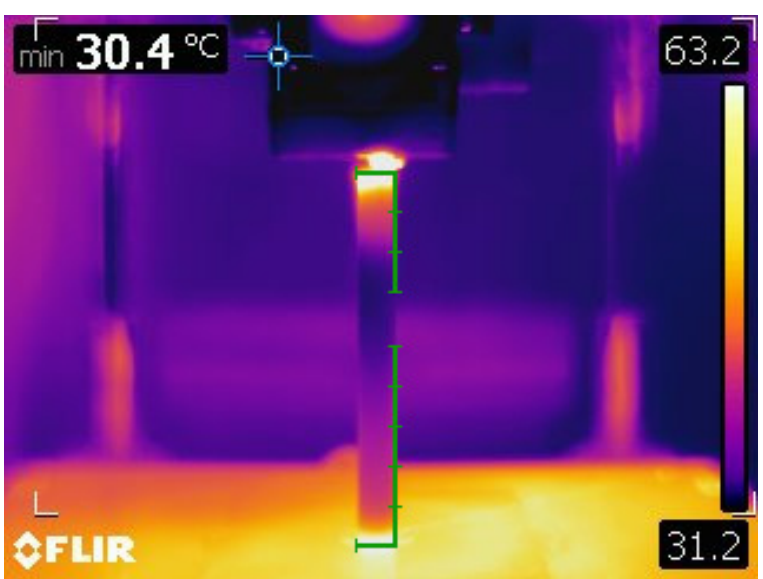

Fig. 6. PLA sample on about $50 \%$ of the printout

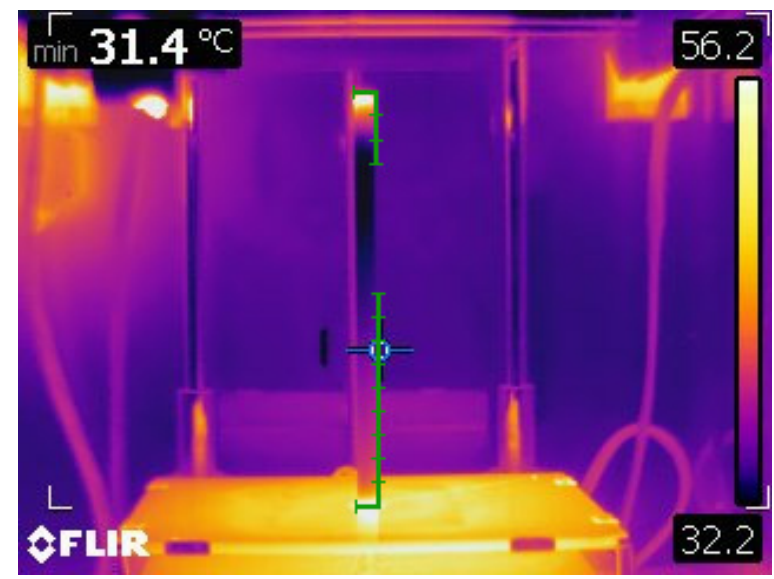

Fig. 7. PLA sample immediately after printing

dimensions were then measured. In order to take into account the effect of taking thermal imaging measurements on the final object (taking pictures each time to open the door that is part of the printer's casing), a control sample was printed on the same print parameters (same .gcode file, same material, same printer without making any changes). The results obtained are shown in Table 1.

Figure 8 shows the ABS sample at the initial printing stage (about $10 \%$ of the print) when the sample height is exactly the equivalent of its two diameters. The temperature is similar to the entire surface of the printed object, no significant temperature changes were observed along with the height.

Table 1. The results of measurements of PLA samples

\begin{tabular}{|c|c|c|}
\hline \multicolumn{3}{|c|}{ PLA samples } \\
\hline Measured value & $\begin{array}{l}\text { Thermovisual } \\
\text { tested sample }\end{array}$ & Control sample \\
\hline $\begin{array}{l}\text { Diameter of the } \\
\text { base }[\mathrm{mm}]\end{array}$ & 10.1 to 10.2 & 10.2 to 10.22 \\
\hline $\begin{array}{l}\text { Diameter in the } \\
\text { middle [mm] }\end{array}$ & 9.64 to 9.7 & 9.52 to 9.6 \\
\hline $\begin{array}{l}\text { Apex diameter } \\
{[\mathrm{mm}]}\end{array}$ & 9.76 to 9.6 & 9.58 to 9.68 \\
\hline $\begin{array}{l}\text { Inside diameter of } \\
\text { the base }[\mathrm{mm}]\end{array}$ & 6.38 & 6.30 \\
\hline $\begin{array}{l}\text { Inside diameter of } \\
\text { the apex [mm] }\end{array}$ & 6.30 & 6.30 \\
\hline Alignment & $\begin{array}{c}\text { visible slight } \\
\text { axial deviations } \\
\text { from approx. } 13 \\
\mathrm{~cm} \text { in height }\end{array}$ & $\begin{array}{c}\text { no visible axial } \\
\text { deviations }\end{array}$ \\
\hline Other & visible seam* & visible seam \\
\hline
\end{tabular}

* seam - a trace that occurs when starting to apply a new layer of filament 


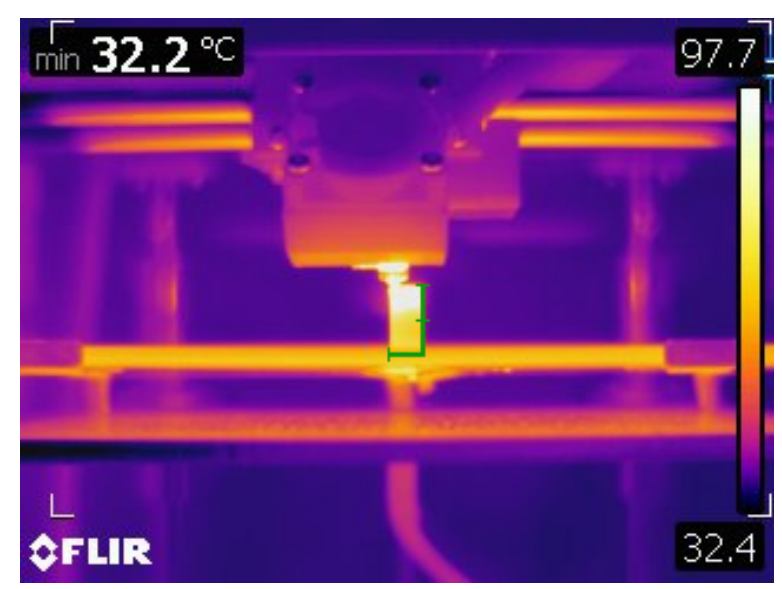

Fig. 8. ABS sample on about $10 \%$ of the printout

Figure 9 illustrates the sample at the $22 \%$ print end stage. At this point, the temperature on the surface of the sample is more varied. It can be divided into two zones: a hot zone, located near the head and table, and a zone resembling a transition zone, occurring on a PLA printed sample. No cold zone has been observed, the sample has a temperature significantly higher than its ambient temperature on its entire surface. The height of the hot zone is about one diameter from the top and about half the diameter from the bottom, the transition zone occupies the remaining part of the sample surface.

Figure 10 illustrates the measurement made during about $53 \%$ of printing completion. It is visible on the trend to keep the material temperature high (relative to the ambient temperature) on the whole height. The hot zone has a height of about one diameter at the top and about three-quarters of the diameter at the bottom. The smallest temperature recorded on the surface of the sample is

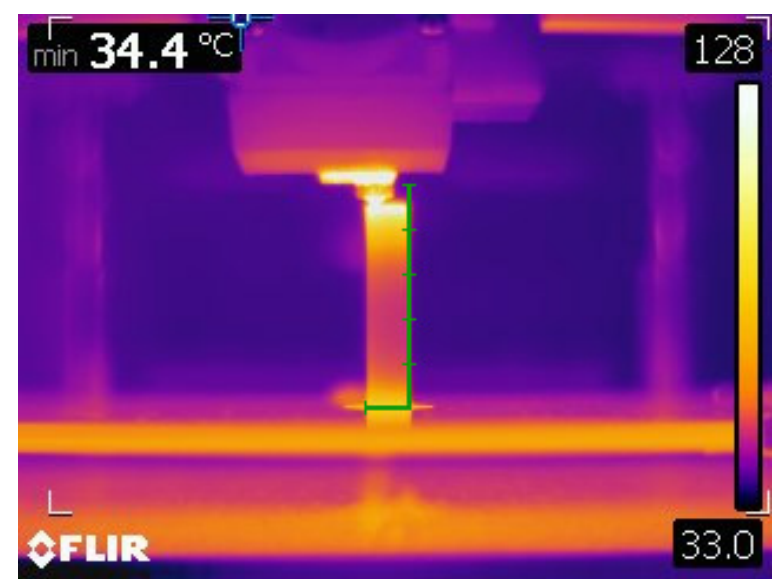

Fig. 9. ABS sample on about $22 \%$ of the printout

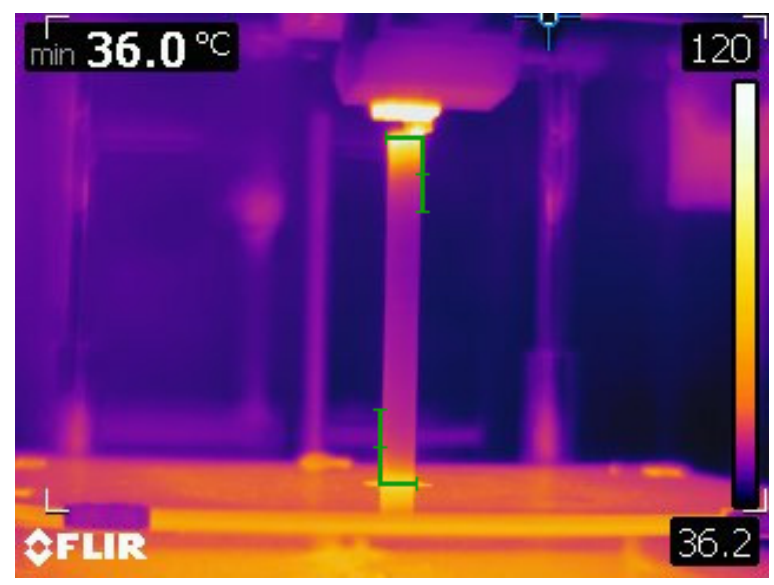

Fig. 10. ABS sample on about $53 \%$ of the printout

about three quarters of its total height at the time of taking this photo. A similar temperature distribution was maintained throughout the print time until its completion and the head was moved to the zero point.

Figure 11 shows the ABS sample immediately after printing. In the left part of the picture at the top, the head is visible, which has moved to its zero position. On the surface of the sample, the temperature profile is different than during the printing process, only after the printing has finished, a cold zone, not previously present, appeared on the surface of the sample. It is most visible at the height of about three quarters of the whole sample in a place that already had the lowest temperature during printing. From the top, a zone of elevated temperature of the material is visible, having a height of about two diameters, it resembles a transition zone existing earlier but without a hot zone in the immediate vicinity. At the bottom there is still a hot

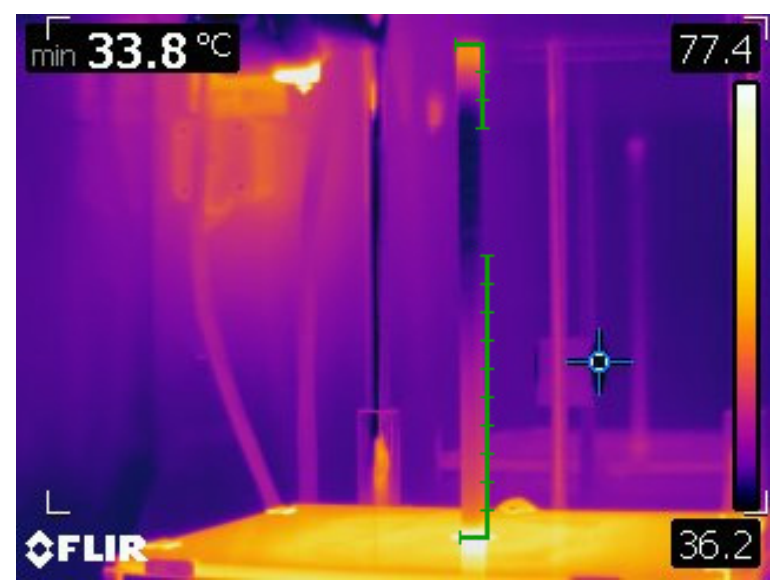

Fig. 11. ABS sample immediately after printing 
Table 2. The results of measurements of ABS samples

\begin{tabular}{|l|c|c|}
\hline \multicolumn{1}{|c|}{ Measured value } & Thermovisual tested sample & Control sample \\
\hline Diameter of the bases [mm] & 10 & 10 \\
\hline Diameter in the middle [mm] & 9.58 to 9.6 & 9.4 to 9.58 \\
\hline Apex diameter [mm] & 9.62 to 9.4 & 9.62 to 9.78 \\
\hline Inside diameter of the base $[\mathrm{mm}]$ & 6.18 & 6.22 \\
\hline Inside diameter of the apex $[\mathrm{mm}]$ & 6.3 & 6 \\
\hline Alignment & $\begin{array}{c}\text { visible axial deviations from } \\
\text { approx. 9.5 cm in height, which } \\
\text { increase from approx. 11 cm }\end{array}$ & $\begin{array}{c}\text { small axial deviations from about } 9.5 \mathrm{~cm} \text { in height, } \\
\text { lesh increase from about } 11.5 \mathrm{~cm} \text {; they are one }\end{array}$ \\
\hline Other & visible seam & thermovisual \\
\hline
\end{tabular}

zone with a height of about one diameter, over which the transition zone is extended to about seven diameters.

After the sample cooled down, it was peeled off the table and the margin of the first layer was removed. As in the case of a sample made of PLA, a control copy was also printed, which was not thermovision tested during the formation. The control printout was made using the same printing parameters (the same .gcode file, the same printer, the same material), the only difference was the lack of opening the door necessary to make measurements. Both samples were measured for geometric dimensions, the results are shown in Table 2.

\section{CONCLUSIONS}

The following conclusions were made on the basis of the conducted research:

1. Even the momentary opening of the printer door during printing has a negative effect on the quality of the printed item.PLA is lesssensitivethan ABS to change external conditions, such as opening the printer's door when printing.

2. The height of the printed object has a large influence on the temperature distribution on its surface. High ABS printouts are the coolest about three quarters of their height.
3. High thin-walled objects are particularly exposed to negative effects due to internal stresses. Objects printed with ABS are most exposed to the occurrence of negative stress effects after exceeding $9.5 \mathrm{~cm}$ of their height.

4. The printing time does not differ significantly when printing from PLA orABS.

5. The difference in temperature at the surface of the printed object from $\mathrm{ABS}$ is lower than in the case of PLA.

\section{REFERENCES}

1. Kosmol, J., Kopytyński, K., Lehrich, K., Dyrbuś, G.: Research on the quality of production using the FDM rapid prototyping method. Prace Naukowe Katedry Budowy Maszyn. Politechnika Śląska,2008, 3, 165-176.

2. Printo H3 - Printo3D.pl access: http://support. printo3d.pl/downloads/h3/PrintoH3_instrukcja obslugi.pdf 04.06.2018.

3. Szulżyk-Cieplak J., Duda A., Sidor B., 3D printers - new possibilities in education.Adv. Sci. Technol. Res. J., 2014, 8(24), 96-101.

4. Siemiński P., Budzik G.: Incremental techniques: 3D printer and printing. Warszawa 2015.

5. Dulski R., Madura H., Piatkowski T., Sosnowski T.:Analysis of a thermal scene using computer simulations.Infrared Physics \& Technology, 49(3), 257-260.

6. Więcek B., De Mey G.:Infrared thermovision: basic and applications. Warszawa 2011. 